\section{Apixaban and eftrenonacog alfa treatment in a patient with moderate hemophilia B and cardiovascular disease}

\author{
Rita C. Santoro, ${ }^{1}$ Mariapia Falbo, ${ }^{1}$ \\ Alessandro Ferraro ${ }^{2}$ \\ ${ }^{1}$ Hemostasis and Thrombosis Unit, and \\ ${ }^{2}$ Cardiology Unit, Azienda Ospedaliera \\ "Pugliese Ciaccio", Catanzaro, Italy
}

\begin{abstract}
In developed countries, the life expectancy of patients with hemophilia $(\mathrm{PwH})$ is now close to that of the unaffected male population. This means that these patients are at risk of developing age-related comorbidities, including cardiovascular disease. Managing cardiovascular disease in $\mathrm{PwH}$ patients can be particularly challenging, due to their high bleeding risk. To our knowledge, this is the first report of a male patient with moderate hemophilia B and hypertensive ischemic heart disease complicated by arrhythmia due to nonvalvular atrial fibrillation, who was treated with apixaban and left atrial appendage closure while receiving concomitant anti-hemorrhagic prophylaxis with eftrenonacog alfa.
\end{abstract}

\section{Introduction}

Since the introduction of clotting factor concentrates and prophylactic therapy, the life expectancy of patients with hemophilia $(\mathrm{PwH})$ in developed countries has increased dramatically; in patients with mild-to-moderate hemophilia, it is very close to that of the general male population. ${ }^{1}$ As a result, there is an increasing number of $\mathrm{PwH}$ patients who present with age-related comorbidities, such as cardiovascular diseases.

In the general population, patients with atrial fibrillation (AF) who are at increased risk of stroke (elevated $\mathrm{CHA}_{2} \mathrm{DS}_{2}$-VASc score) are usually treated with antithrombotic agents, with individualized treatment based on the patient's risk of stroke and bleeding events, as well as their preferences. ${ }^{2}$ However, the increased bleeding propensity in $\mathrm{PwH}$ makes antithrombotic therapy difficult to manage.

Here, we present a male patient with hemophilia B, with a history of acute coronary syndrome and poorly managed hemophilia, who at age 69 years was confirmed to have hypertensive ischemic heart disease complicated by arrhythmia due to nonvalvular AF (NVAF). To our knowledge, this is the first report of a patient with hemophilia B being successfully managed with the anticoagulant apixaban and while receiving concomitant anti-hemorrhagic prophylaxis with eftrenonacog alfa.

\section{Case Report}

In 2006, a 56-year old male patient with moderate hemophilia B (coagulation factor IX [FIX] activity 3.5\%) presented with acute coronary syndrome and underwent surgery for a drug-eluting stent (DES). After the procedure, he was started on dual antiplatelet therapy with aspirin $100 \mathrm{mg}$ daily and clopidogrel $75 \mathrm{mg}$ daily. Tests for prothrombotic mutations (Factor V Leiden and prothrombin gene [G20210A]) and lupus anticoagulant were negative, and physiologic coagulation inhibitors were in the normal range. Hyperhomocysteinemia was detected. The patient refused prophylactic treatment with standard half-life (SHL) recombinant factor IX (rFIX) concentrate.

More than 1 year after the DES implantation, he was admitted to the emergency department (ED) for melena and severe anemia. He had maintained dual antiplatelet therapy. Aspirin was discontinued, while clopidogrel was maintained. The patient was again offered prophylactic treatment with SHL rFIX, which he refused. He was subsequently lost to follow-up for several years.

Five years later, the patient presented to the ED with epistaxis, which had continued for several days. The patient was still taking clopidogrel. The epistaxis stopped after receiving SHL rFIX replacement therapy. The patient once again declined to begin rFIX prophylaxis when it was offered.

The patient subsequently presented with hematuria and was diagnosed with lowgrade transitional cell carcinoma, for which he underwent curative resection. In 2017, he was diagnosed with basal cell carcinoma and underwent resection of a growth on the pinna of the right ear.

In February 2019, the patient (now aged 69 years; weight $67 \mathrm{~kg}$; FIX 3.5\%) attended a follow-up appointment. The patient's treatment timeline following this visit is summarized in Figure 1. At this follow-up, he was still receiving clopidogrel $75 \mathrm{mg}$ daily, and laboratory testing revealed polyglobulia of undetermined etiology (white blood cells $5.42 \times 10^{3} / \mu \mathrm{L}$; red blood cells $7.25 \times 10^{6} / \mu \mathrm{L}$; hemoglobin $18.1 \mathrm{~g} / \mathrm{dL}$; hema-
Correspondence: Rita Carlotta Santoro, Hemostasis and Thrombosis Unit, Azienda Ospedaliera "Pugliese Ciaccio" Viale Pio X, 83 - 88100 Catanzaro CZ, Italy.

Tel.: +39.0961722180 - Fax: +39.0961883093 E-mail: ritacarlottasantoro@gmail.com

Key words: Apixaban, atrial fibrillation, factor IX Fc fusion protein, hemophilia B, cardiovascular surgical procedures.

Acknowledgements: We would like to thank Toni Dando of Springer Healthcare Communications, who wrote the first draft of this report. This medical writing assistance was funded by Sobi.

Contributions: All authors meet the criteria for authorship as established by the International Committee of Medical Journal Editors. RCS followed the patient throughout all clinical phases, including the follow-up, and made the clinical-therapeutic decisions. MF carried out all the laboratory tests. $\mathrm{AF}$ is the cardiologist who performed left atrial appendage closure and cardioversion, also providing the cardiological consultations. All authors read and approved the final manuscript.

Conflicts of interest: The authors declare no potential conflict of interest.

Funding: Funding for the preparation of this manuscript was provided by Sobi.

Consent for publication: The patient gave his consent for all clinical information relating to his case to be reported in a medical publication.

Availability of data and materials: Data from this case report are available from the authors upon reasonable request.

Received for publication: 7 April 2021. Accepted for publication: 30 August 2021.

This work is licensed under a Creative Commons Attribution-NonCommercial 4.0 International License (CC BY-NC 4.0).

(C) Copyright: the Author(s), 2021

Licensee PAGEPress, Italy

Hematolooy Reports 2021: 13:9169

doi:10.4081/hr:2021.9169

tocrit $56.2 \%$; platelets $143 \times 10^{3} / \mu \mathrm{L}$ ). Myeloproliferative disease was ruled out as no $J A K 2, C A L R$, or $M P L$ gene mutations were detected. Physical examination revealed an irregular pulse, and an electrocardiogram and cardiologic assessment confirmed hypertensive ischemic heart disease complicated by arrhythmia due to NVAF, with uncertain time of onset. He was 
at high thrombotic risk $\left(\mathrm{CHA}_{2} \mathrm{DS}_{2}\right.$-VASc score of 3; Figure 2A) and hemorrhagic risk (HAS-BLED score of 3; Figure 2B).

Therefore, in March 2019, the patient started a treatment regimen consisting of eftrenonacog alfa (rFIXFc, 3500 U/week) in combination with anticoagulation therapy (apixaban $2.5 \mathrm{mg}$ every 12 hours). In June 2019, after preoperative infusion of $5000 \mathrm{U}$ of rFIXFc, followed by $3500 \mathrm{U}$ at 24 and 48 hours, he underwent a successful closure of the left atrial appendage (LAA) and cardioversion. The procedure was performed as follows. A delivery catheter was inserted under general anesthesia via the femoral vein; heparin (5000 IU) and ceftriaxone (2 g) were administered intravenously. As transesophageal echocardiography revealed no thrombus formation inside the LAA, the catheter was advanced until it reached the right atrium. An interatrial septum puncture was then performed to allow the catheter to reach the left atrium. No pleural effusions or atrioventricular conduction disturbances were detected, and there were no other procedure-related adverse events. The patient continued to receive apixaban and rFIXFc (3500 U/week) after the procedure.

According to the cardiologist's prescription, apixaban was discontinued 1 month after the procedure (total treatment time of 5 months), while aspirin and clopidogrel were resumed. The patient continued to receive $\mathrm{rFIXFc}$ prophylaxis due to his earlier episodes of bleeding with clopidogrel monotherapy.

On 10 October 2019, in consultation with his cardiologist, the patient discontinued aspirin and continued antiplatelet therapy with clopidogrel alone. At the same time, the prophylaxis regimen was reduced to rFIXFc $3500 \mathrm{U}$ every 10 days (trough levels of $5 \%$ ), which was considered to not increase his thrombotic risk.

At the most recent follow-up visit (nearly 18 months after LAA closure), the patient was well, and continued to receive both clopidogrel and rFIXFc (the latter reduced to once every 2 weeks), with no adverse events reported.

\section{Discussion}

Although there are conflicting reports, there is evidence to suggest that severe hemophilia reduces the risk of ischemic heart disease; however, the risk in patients with non-severe hemophilia appears to be similar to that observed in the general population. ${ }^{3}$ The prevalence of $\mathrm{AF}$ in $\mathrm{PwH}$ patients is also similar to that found in individuals without hemophilia. ${ }^{3}$ Furthermore,
PwH are exposed to the same cardiovascular risk factors as the general population; indeed, because of an often more sedentary lifestyle imposed by arthropathy, $\mathrm{PwH}$ patients have an increased prevalence of risk factors such as hypertension and obesity. ${ }^{3,4}$

Due to their increased bleeding propensity, the management of cardiovascular conditions in $\mathrm{PwH}$ is challenging and there are currently no evidence-based guidelines. Given the relatively small number of such patients, it appears unlikely that there will be any large clinical trials conducted in the near future. Thus physicians must treat patients on a case-by-case basis, and rely on personal or anecdotal experience, consensus recommendations, and ongoing registry studies for guidance. ${ }^{3-6}$ Consensus papers have recommended that $\mathrm{PwH}$ patients are managed by a multidisciplinary team, including a hemophilia specialist and a cardiologist. 4,6

When considering initiating antithrombotic treatment for AF in $\mathrm{PwH}$, it is generally recommended that a higher CHADS2/CHA $2 \mathrm{DS}_{2}$-VASc score threshold is used than in the general population; addi-

2019

\begin{tabular}{|c|c|c|c|c|c|c|}
\hline 27 February & 6 March & 11 March & 4 June & 12 June & 2 July & 10 October \\
\hline $\begin{array}{l}\text { Follow up } \\
\text { appointment }\end{array}$ & Phlebotomy & $\begin{array}{c}\text { Initiated rFIXFc } \\
3000 \\
\text { units/week }\end{array}$ & $\begin{array}{c}\text { Preoperative } \\
\text { rFIXFc } 5000 \\
\text { units }\end{array}$ & $\begin{array}{l}\text { rFIXFc } 3500 \\
\text { units/week }\end{array}$ & $\begin{array}{l}\text { Discontinued } \\
\text { apixaban, }\end{array}$ & $\begin{array}{l}\text { Discontinued } \\
\text { aspirin }\end{array}$ \\
\hline \multirow[t]{2}{*}{$\begin{array}{c}\text { Continued to } \\
\text { receive } \\
\text { dopidogrel } \\
75 \mathrm{mg} / \mathrm{day}\end{array}$} & & $\begin{array}{c}+ \\
\text { Apixaban } \\
2.5 \mathrm{mg} / 12 \\
\text { hours }\end{array}$ & $\begin{array}{c}\downarrow \\
\text { Auricular } \\
\text { closure and } \\
\text { cardioversion }\end{array}$ & $\begin{array}{l}\text { Continued to } \\
\text { receive } \\
\text { apixaban }\end{array}$ & $\begin{array}{l}\text { Initiated } \\
\text { aspirin + } \\
\text { clopidogrel }\end{array}$ & $\begin{array}{l}\text { Continued to } \\
\text { receive } \\
\text { clopidogrel }\end{array}$ \\
\hline & & & $\begin{array}{c}\text { intervention } \\
\downarrow \\
\text { Postoperative } \\
\text { rFIXFc } 3500 \\
\text { units } 24 \text { and } \\
48 \text { hours after }\end{array}$ & & $\begin{array}{c}\text { Continued to } \\
\text { receive rFIXFC } \\
3500 \\
\text { units/week }\end{array}$ & $\begin{array}{c}\text { rFIXFc dose } \\
\text { reduced to } \\
3500 \text { units } / 10 \\
\text { days }\end{array}$ \\
\hline
\end{tabular}

Figure 1. The patient's treatment timeline for 2019. rFIXFc, eftrenonacog alfa.

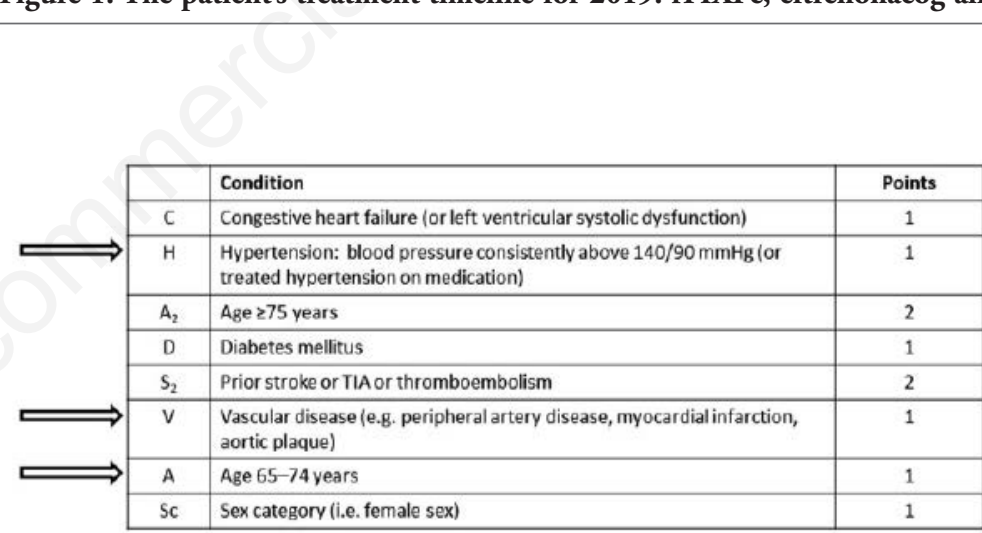

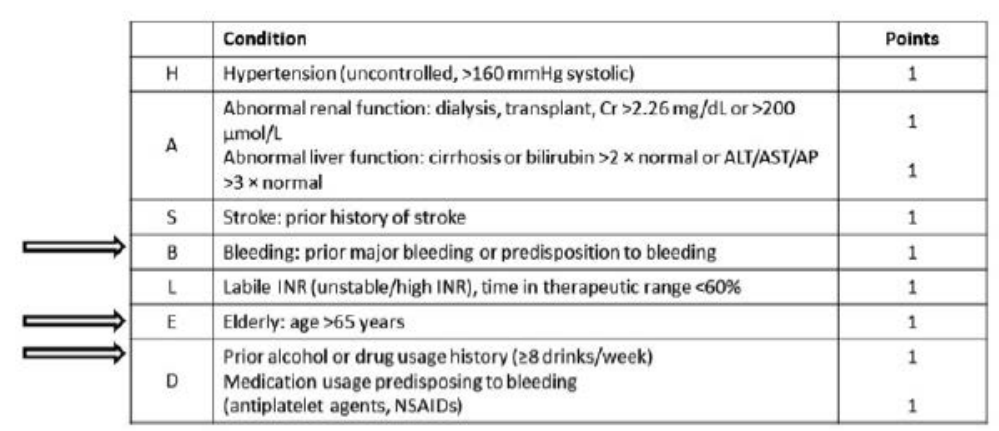

Figure 2. The patient's (A) CHA2DS2-VASc score and (B) HAS-BLED score in March 2019. His risk factors are indicated by arrows. ALT, alanine aminotransferase; AP, alkaline phosphatase; AST, aspartate aminotransferase; Cr, creatinine; INR, international normalized ratio; NSAID, non-steroidal anti-inflammatory drug; TIA, transient ischemic attack. 
tionally, the patient's coagulation factor levels must be taken into account. ${ }^{3,4}$ It should also be noted that HAS-BLED scores are likely to substantially underestimate the risk of bleeding in PwH. ${ }^{6}$ Low-dose aspirin has been safely used in patients with mild and moderate hemophilia; ${ }^{3}$ however, the reduction in the risk of stroke afforded by aspirin is inadequate. ${ }^{4}$ Oral anticoagulant agents provide better stroke protection than antiplatelet treatment in patients with $\mathrm{AF}$ and have a lower bleeding risk than warfarin, although there is limited evidence regarding their use in $\mathrm{PwH}^{4}$

For our patient, we selected a direct oral anticoagulant rather than vitamin $\mathrm{K}$ antagonists, as the latter agents are known to reduce plasma FIX levels in hemophilia B, thereby increasing the severity of hemophilia and the risk of intracranial hemorrhage. ${ }^{7}$ More specifically, low-dose apixaban (with rFIXFc prophylaxis) was chosen for its favorable safety profile, including a lower bleeding risk than most other direct anticoagulants. ${ }^{7}$ Although there are no formal clinical data on the use of apixaban in $\mathrm{PwH}$, the efficacy and safety of apixaban have been demonstrated in clinical trials of patients with AF. In a large trial in patients with AF who were not eligible for warfarin treatment, apixaban was significantly more effective than aspirin at reducing the risk of systemic embolism and stroke, with no increase in the risk of major bleeds or intracranial hemorrhage. ${ }^{8}$ In another trial, apixaban was also significantly more effective than warfarin at reducing the risk of systemic embolism and stroke in patients with $\mathrm{AF}$, with a significant reduction in major bleeding and mortality. ${ }^{9}$

In addition to treatment with apixaban for 5 months, our patient underwent LAA closure and cardioversion. LAA closure has been used to reduce the risk of stroke in patients with AF for whom long-term anticoagulant treatment is unsuitable, making it a promising option for $\mathrm{PwH}$. In one case, a 60-year old woman with mild hemophilia B and symptomatic AF underwent a combined pulmonary vein isolation and LAA occlusion using the Watchman device. ${ }^{10}$ She received rFIX and warfarin for 1 month after the procedure; she was not prescribed any antiplatelet agents as her bleeding risk was too high. A 6-month check-up revealed no complications and no further $\mathrm{AF}$ episodes. ${ }^{10}$ In another case, a 67 -year old man with hemophilia A, permanent $\mathrm{AF}$, and a history of hypertension and heart failure, who was receiving regular factor VIII (FVIII) replacement therapy, underwent LAA closure with the Amplatzer Amulet device as an alternative to oral anticoagulation therapy. ${ }^{11} \mathrm{He}$ received dual antiplatelet therapy with clopidogrel and aspirin for 1 month after the procedure, followed by 2 months of aspirin. After 1 year, he had experienced no thrombotic or bleeding complications, nor were there any adverse events related to the LAA closure. In addition to these cases in $\mathrm{PwH}$, there have been reports of successful LAA closure in patients with hereditary hemorrhagic telangiectasia. $^{12,13}$

\section{Conclusions}

To the best of our knowledge, this is the first reported case of a patient with hemophilia B and cardiovascular disease being treated with apixaban, closure of the LAA, and cardioversion. The increased bleeding risk posed by anticoagulant therapy was successfully managed with rFIXFc prophylaxis, and no hemorrhagic complications were reported.

\section{References}

1. Darby SC, Kan SW, Spooner RJ, et al. Mortality rates, life expectancy, and causes of death in people with hemophilia A or B in the United Kingdom who were not infected with HIV. Blood 2007; 110:815-25.

2. January CT, Wann LS, Calkins H, et al. 2019 AHA/ACC/HRS Focused Update of the 2014 AHA/ACC/HRS Guideline for the management of patients with atrial fibrillation: a report of the American College of Cardiology/American Heart Association Task Force on Clinical Practice Guidelines and the Heart Rhythm Society in collaboration with the Society of Thoracic Surgeons. Circulation 2019;140:e125-51.

3. Schutgens REG, Voskuil M, MauserBunschoten EP. Management of cardiovascular disease in aging persons with haemophilia. Hamostaseologie
2017;37:196-201.

4. Ferraris VA, Boral LI, Cohen AJ, et al. Consensus review of the treatment of cardiovascular disease in people with hemophilia A and B. Cardiol Rev 2015;23:53-68.

5. Mannucci PM, Schutgens REG, Santagostino E, et al. How I treat agerelated morbidities in elderly persons with hemophilia. Blood 2009;114:5256-63.

6. Schutgens RE, Klamroth R, Pabinger I, et al. Management of atrial fibrillation in people with haemophilia - a consensus view by the ADVANCE Working Group. Haemophilia 2014;20:e417-20.

7. Aguilar C. Might apixaban be the optimal oral anticoagulant for haemophiliacs with atrial fibrillation? Haemophilia 2015;21:e338-e40.

8. Connolly SJ, Eikelboom J, Joyner C, et al. Apixaban in patients with atrial fibrillation. N Engl J Med 2011;364:80617.

9. Granger CB, Alexander JH, McMurray $\mathrm{JJV}$, et al. Apixaban versus warfarin in patients with atrial fibrillation. N Engl J Med 2011;365:981-92.

10. Bhatti Z, Goldbarg S. Combined left atrial appendage closure and ablation in a patient with hemophilia B, paroxysmal atrial fibrillation, and transient ischemic attack. HeartRhythm Case Rep 2019;5:266-8.

11. Güray Ü, Korkmaz A, Gürsoy HT, et al. Percutaneous left atrial appendage closure in a patient with haemophilia and atrial fibrillation: a case report. Eur Heart J Case Rep 2019;3:ytz124.

12. Mielczarek M, Gałąska R, Drewla P, et al. Left atrial appendage occlusion in a patient with hereditary hemorrhagic telangiectasia and atrial fibrillation - a therapeutic option worth considering. Arch Med Sci Atheroscler Dis 2017;2:e29-30.

13. Bosi D, Cozza F, Menozzi A, et al. Percutaneous left atrial appendage closure in a patient with atrial fibrillation and Rendu-Osler-Weber disease [in Italian]. G Ital Cardiol (Rome) 2019;20:36s-9s. 